\title{
Cognitive problems in alcohol use: a review
}

\begin{abstract}
Alcohol use has increased in the recent years which have lead to several problems worldwide. Effect on cognition is such an area which has not been studied much but there has been ample evidences regarding it. Various studies show the effect of alcohol on cognitive performances which depends on various factors like age, sex, amount and pattern of drinking and the related medical co-morbidities. Various results have been obtained depending on the amount of alcohol consumed and relationship has been seen on their effect on medical co-morbidities. Despite a substantial amount of research in the field no robust data could be validated due to lack of definition of a standard drink across studies of various countries. Nevertheless it has been seen that alcohol does have a detrimental effect on cognition which has even been proved indirectly by functional studies. With present methods of cognitive ability testing and other functional imaging studies being used we are hopeful that in recent future we will be able to pinpoint the problems caused and thus have a future direction for necessary interventions.
\end{abstract}

Keywords: alcohol, cognition, binge drinking, $j$-shaped relationship, visuo-spatial abilities, working memory
Volume 5 Issue 6 - 2018

\author{
PK Dalal,'Anamika Das \\ 'Department of Psychiatry, King George's Medical University, \\ India \\ 2Junior Resident, Department of Psychiatry, King George's \\ Medical University, India
}

Correspondence: Dalal PK, Professor and Head, Department of Psychiatry, King George Medical University Tel 0522-2258805, Fax 0522-2258805, India,

Email docpkdalal@gmail.com

Received: October 31, 2018 | Published: December 19, 2018

\section{Introduction}

Recent decades have shown an increasing trend in alcohol consumption, with the highest burden on developing countries. Prevalence of alcohol abuse is five to seven per cent in the Indian population with an estimated 10-20 million in need for treatment. In the Indian subcontinent alcohol dependence have even accounted for $1.2 \%$ of the deaths. It has been seen that any level of alcohol consumption can lead to various degrees of cognitive problem and this is of concern due to the wide use of alcohol. ${ }^{2}$

\section{Discussion}

Mild-to-moderate impairment in intellectual functioning was seen in alcohol users. ${ }^{3}$ There was also reduction in size of the brain and changes in brain activity in those individuals. The most common difficulty found in alcohol users was in visuospatial abilities and higher cognitive functioning. ${ }^{4}$ Visuospatial abilities refer to perceiving an object and in a way remembering how it is located in 2- and 3-dimensional space. The ability to organize and then set in motion and if needed to change comprises the abstract thinking which forms a part of higher cognition. It was seen that individuals with a binge drinking pattern have impairments in tasks like working memory, planning, attention, and decision making. ${ }^{5}$ It was proposed that the effects of alcohol on cognition lies on a continuum from light functional deterioration to cognitive deficits which are serious depending on the amount of drink consumed. ${ }^{6}$ Some studies reported deficits in concept formation and abstraction in young-to middle-aged men who were engaged even in social drinking.?

An increasing number of reports now suggest a J-shaped relationship between cognition and amount of alcohol consumed, suggesting that low to moderate drinking can be beneficial for cognition than non-drinking or heavy drinking. ${ }^{8-10}$ In contrast, there are several studies that shows that these benefits are limited and condition-specific. ${ }^{11}$ Launer et al. ${ }^{12}$ found that cognitive function was improved by alcohol only in patients of cardiovascular diseases or diabetes mellitus, while some have reported a benefit only in elderly women. ${ }^{13,14}$ Some studies, moreover, found that light-to-moderate alcohol intake reduced the chances of dementia. ${ }^{15}$ Several attempts were done to define a safe dose for alcohol but has been inconsistent. A review of 19 published studies have shown that 5 or 6 "standard drinks" per day caused "cognitive inefficiencies", 7 to 9 drinks caused "mild cognitive deficits", and 10 or more drinks caused impaired cognition of a degree which is found in frank alcoholics. The relation between duration and lifetime quantity of drinking and cognition is somewhat not very clear. Some studies said that cognitive performance worsens directly in proportion to the amount and duration of alcohol intake ${ }^{16}$ Some have suggested that cognitive deficits may be found only in those who drink regularly for 10 years or more. ${ }^{17,18}$ Although further research is needed to determine how a person's pattern of drinking is related to cognitive impairment, some deficits are possible even in people who are not heavy drinkers.

Structural imaging evidences consistently revealed that alcoholics' brains are smaller and less dense than non-alcohol users. ${ }^{19,20}$ Loss of brain volume is specific in two areas: the outer layer (i.e., the cortex) of the frontal lobe, a major centre of higher mental functions $;^{20-22}$ and the cerebellum. It is supported by functional imaging studies, which revealed altered brain activity in both these areas. ${ }^{23}$ Functional imaging is also sensitive enough to detect these abnormalities even prior to structural imaging techniques, or even when major cognitive problems are not prominent. Thus functional imaging may be useful for detecting early stages of cognitive decline. ${ }^{23}$

It is difficult to exactly measure cognitive abilities and to relate these abilities to any brain irregularity. ${ }^{24}$ This has lead to development of better techniques for measuring cognition. Beatty and colleagues ${ }^{16}$ showed that cognitive impairment may be caused due to use of alcohol, by damage to multiple brain areas like prefrontal circuits. It has been seen that some of these impairment is reversible when abstinent. ${ }^{25}$ Newly detoxified alcohol users show mild but significant deficits in 
problem-solving, short-term memory, and visuospatial abilities. ${ }^{26}$ By remaining abstinent brain function is recovered by several months to 1 year ${ }^{27}$-with improvements in working memory, visuospatial functioning, and attention. This is accompanied by increase in volume of brain, when compared with alcohol users who have been treated but have relapsed. ${ }^{26}$ Reversibility may occur due to reorganization of important brain-cell networks. It is evident that such reorganization sometimes contributes to the success of treatment.

The exact role of cognitive function in treatment of alcohol has been unclear. It was seen that patients who had problem in cognition had difficulty in comprehending the information imparted during therapy and thus may not make their full use thus impeding recovery. Other view says that cognitive functioning does not influence treatment outcome directly, but may have an impact on factors which may in turn contribute to success of treatment. ${ }^{28}$ Cognitive impairment is most severe in the first weeks of abstinence, thus making it difficult to benefit from educational and skill-development sessions during that period. $^{29}$

\section{Conclusion}

Thus it is seen that the effect of alcohol on cognition is varied and depends on a number of variables like the age, sex, pattern of drinking, amount and duration of drinking, medical co-morbidities present etc.. The variation in the definition of standard drink over several studies questions the validity of the effect of amount of alcohol consumption on cognition. The amount of alcohol in a standard drink is different over countries, and no standard definition exists to define low to moderate drinking; thus, studies examining the effects of alcohol on cognition have a varying result. It is, therefore, critical to have standardised definitions to increase validity over studies. ${ }^{11}$ whatsoever it has been seen that even mild-to-moderate drinking can affect cognitive functioning in an adverse way. Persistent cognitive impairment leads to poor job performance in adult alcohol users, and can hamper the learning and academic achievement in adolescents with heavy drinking. ${ }^{30}$ It has been shown that cognitive impairment may in stand in way of recovery, although robust evidences are not available. Practical strategies are needed to deal with this combination of alcoholism and cognitive impairment and it requires a detailed understanding of the nature of cognitive functions and the interactions it have in structural and functional brain abnormalities and in this way find out probable solutions for the same. It is hoped that future researches will give more evidence and insight in the relationship of alcohol consumption and cognitive impairment, but it is highly imperative that intervention for individuals with problematic alcohol use behaviour may play a significant role in prevention of cognitive impairment in that population.

\section{Acknowledgments}

None.

\section{Conflicts of interest}

Author declares that there are no conflicts of interest.

\section{References}

1. Grover S, Bhateja G, Basu D. Pharmacoprophylaxis of alcohol dependence: review. Indian J Psychiatry. 2007;49:19-25.

2. Gordis E. NIAAA 25th Anniversary: Advances in the Neuroscience of Alcohol. Alcohol Clin Exp Res. 1996;20(8 Suppl):38A-44A.
3. Parsons OA. Neurocognitive deficits in alcoholics and social drinkers: A continuum? Alcohol Clin Exp Res. 1998;22(4):954-961.

4. Oscar Berman M, Shagrin B, Evert DL, Epstein C. Impairments of brain and behavior: The neurological effects of alcohol. Alcohol Health Res World. 1997;21(1):65-75.

5. Gil Hernandez S, Garcia Moreno LM. Executive performance and dysexecutive symptoms in binge drinking adolescents. Alcohol. 2016;51:7987.

6. Ryback RS. The continuum and specificity of the effects of alcohol on memory. A review. Q J Stud Alcohol. 1971;32:995-1016.

7. Parker ES, Noble EP. Alcohol and the aging process in social drinkers. $J$ Stud Alcohol. 1980;41(1):170-178.

8. Mukamal KJ, Longstreth WT Jr, Mittleman MA, et al. Alcohol consumption and subclinical findings on magnetic resonance imaging of the brain in older adults: the cardiovascular health study. Stroke. 2001;32(9):19391946.

9. Ruitenberg A, van Swieten JC, Witteman JC, et al. Alcohol consumption and risk of dementia: the Rotterdam Study. Lancet. 2002;359(9303):281286.

10. Kalmijn S, van Boxtel MP, Verschuren MW, et al. Cigarette smoking and alcohol consumption in relation to cognitive performance in middle age. Am J Epidemiol. 2002;156(10):936-944.

11. Gil-Hernandez S, Garcia Moreno LM. Executive performance and dysexecutive symptoms in binge drinking adolescents. Alcohol. 2016;51:79-87.

12. Launer LJ, Feskens EJ, Kalmijn S, Kromhout D. Smoking, drinking, and thinking. The Zutphen Elderly Study. Am J Epidemiol. 1996;143(3):219_ 227.

13. McGuire LC, Ajani UA, Ford ES. Cognitive functioning in late life: the impact of moderate alcohol consumption. Ann Epidemiol. 2007;17(2):93-99.

14. Dufouil C, Ducimetiere P, Alperovitch A. Sex differences in the associa $\neg$ tion between alcohol consumption and cognitive performance. EVA Study Group. Epidemiology of Vascular Aging. Am J Epidemiol. 1997;146(5):405-412.

15. Brust J. Ethanol and Cognition: Indirect Effects, Neurotoxicity and Neuroprotection: A Review. Int $J$ Environ Res Public Health. 2010;7(4):1540-1557.

16. Beatty WW, Tivis R, Stott HD, et al. Neuropsychological deficits in sober alcoholics: Influences of chronicity and recent alcohol consumption. Alcohol Clin Exp Res. 2000;24(2):149-154.

17. Parsons OA, Nixon SJ. Cognitive functioning in sober social drinkers: A review of the research since 1986. J Stud Alcohol. 1998;59(2):180-190.

18. Eckardt MJ, File SE, Gessa GL, et al. Effects of moderate alcohol consumption on the central nervous system. Alcohol Clin Exp Res. 1998;22(5):998-1040.

19. Pfefferbaum A, Rosenbloom M, Crusan K, et al. Brain CT changes in alcoholics: Effects of age and alcohol consumption. Alcohol Clin Exp Res. 1988;12(1):81-87.

20. Pfefferbaum A, Lim KO, Zipursky RB, et al. Brain gray and white matter volume loss accelerates with aging in chronic alcoholics: A quantitative MRI study. Alcohol Clin Exp Res. 1992;16(6):1078-1089.

21. Oscar Berman M, Shagrin B, Evert DL, Epstein C. Impairments of brain and behavior: The neurological effects of alcohol. Alcohol Health Res World. 1997;21(1):65-75.

22. Lyvers M. Loss of control" in alcoholism and drug addiction: A neuroscientific interpretation. Exp Clin Psychopharmacol. 2000;8(2):225-249. 
23. Eberling JL, Jagust WJ. Imaging studies of aging, neurodegenerative disease, and alcoholism. Alcohol Health Res World. 1995;19(4):279-286.

24. Parsons OA. Determinants of cognitive deficits in alcoholics: The search continues. Clin Neuropsychologist. 1994;8(1):39-58.

25. Volkow N, Wang GJ, Doria JJ. Monitoring the brain's response to alcohol with positron emission tomography. Alcohol Health Res World. 1995;19(4):296-299.

26. Sullivan EV, Rosenbloom MJ, Lim KO. Longitudinal changes in cognition, gait, and balance in abstinent and relapsed alcoholic men: Relationships to changes in brain structure. Neuropsychology. 2000;14(2):178188 .

27. Sullivan EV, Rosenbloom MJ, Pfefferbaum A. Pattern of motor and cognitive deficits in detoxified alcoholic men. Alcohol Clin Exp Res. 2000;24(5):611-621
28. Allen DN, Goldstein G, Seaton BE. Cognitive rehabilitation of chronic alcohol abusers. Neuropsychol Rev. 1997;7(1):21-39.

29. McCrady BS, Smith DE. Implications of cognitive impairment for the treatment of alcoholism. Alcohol Clin Exp Res. 1986;10(2):145-149.

30. Giancola PR, Moss HB. Executive cognitive functioning in alcohol use disorders. Recent Dev Alcohol. 1998;14:227-251.

31. Kim S, Kim Y, Park SM. Association between alcohol drinking behaviour and cognitive function: results from a nationwide longitudinal study of South Korea. BMJ Open. 2016;6:e010494. 